\title{
Tumors of the eyelid - a histopathological study at tertiary care hospitals in Dhaka, Bangladesh
}

\author{
Rita Paul $^{1}$, Md. Nasimul Islam¹, Enamul Kabir ${ }^{1}$, Harunur Rashid Khan ${ }^{1}$, Utpal Kumar Kundu² \\ ${ }^{I}$ Department of Pathology, Sir Salimulla Medical College, Dhaka, Bangladesh \\ ${ }^{2}$ Department of Ophthalmology, Sir Salimulla Medical College, Dhaka, Bangladesh
}

\begin{abstract}
Background and objective: Eyelid growth is a common clinical condition presented to ophthalmologists. Accurate diagnosis of eyelid tumors is necessary to guide ophthalmologists to design optimal management. We carried out the study to assess the histopathological types of different eyelid growth in tertiarycare hospitals of Dhaka city.

Methods: This is a cross sectional study performed at the Department of Pathology of Sir Salimullah Medical College (SSMC), Dhaka, Bangladesh. Samples were collected from hospitals of SSMC and National Institute of Ophthalmology (NIO), Dhaka, Bangladesh. Study period was from January 2012 to December 2013. A total of 93 cases with eyelid growth of both sex were enrolled in the study. After obtaining informed written consent, tumors were excised by the ophthalmologist and the specimens were collected in $10 \%$ formalin for histopathological examination.

Results: A total of 93 cases of eyelid lesions were examined. The most common age group affected was between 26-50yrs (50.54\%). Mean age was 43.22 \pm 17.42 (range 19 - 90 years). Gender distribution of the patients was almost equal (male $51.6 \%$, female $48.4 \%$ ). Neoplastic lesions were found in 86 cases $(92.47 \%)$ and non neoplastic growth was present in $7(7.53 \%)$ cases. Benign, pre-malignant and malignant tumors were found in $52(55.91 \%), 01(1.08 \%)$ and $33(35.48 \%)$ cases respectively. Among the malignant lesions, basal cell carcinoma was the most common malignant tumor $(36.4 \%)$ followed by sebaceous gland and squamous cell carcinoma (27.3\%). Nevus was the most common benign lesions (26.9\%) followed by sudoriferous cyst (19.2\%) and haemangioma (15.4\%).
\end{abstract}

Conclusions: All the eyelid lesions removed surgically should be examined histopathologically to establish the correct diagnosis. Accurate diagnosis of specific tumors is important for proper treatment and favorable prognosis.

IMC J Med Sci 2017; 11(1): 5-10

\section{Introduction}

Eyelid growth is a common clinical condition presented to ophthalmologists [1]. The eyelid is rich in glandular tissue which includes sweat glands of the eyelid skin, lacrimal gland of Krause and Wolfring, the apocrine gland of Moll, meibomian and the glands of Zeiss [2]. Pathologic conditions affecting the eyelid may be inflammatory or neoplastic. It has been reported that $90 \%$ of skin cancers occurs in head and neck region and $10 \%$ of them are located at eyelid level [2]. Benign epithelial lesions, cystic lesions, and benign melanocytic lesions of eyelid are very common [3]. Among the benign lesions, squamous cell papilloma, seborrheic keratosis, melanocytic nevus are common. Most common malignant

\section{Address for Correspondence:}

Dr. Rita Paul, Assistant Professor, Department of Pathology, Ibrahim Medical College, 122 Kazi Nazrul Islam Avenue, Shahbag, Dhaka, Bangladesh.E-mail: ritapaul16@gmail.com 
tumors of eyelid are basal cell carcinoma, squamous cell carcinoma and sebaceous carcinoma. Other less common malignant tumours include merkel cell carcinoma, lymphoma and secondary metastatic carcinoma [4].

Most of the eyelid tumors are of cutaneous origin, mostly epidermal, which can be divided into epithelial and melanocytic tumors. Basal cell carcinoma, benign epithelial lesions, cystic lesions, and melanocytic lesions represent about $85 \%$ of all eyelid tumors [5]. Inflammatory and infectious lesions simulating neoplasm are also common. Basal cell carcinoma is the most common malignancy of eyelid. It occurs most frequently in lower eye-lid, followed by medial canthus, upper eye-lid and lateral canthus [6]. Squamous cell carcinoma usually involves the lower lid margin in elderly fair-skinned persons. It most commonly arises from premalignant lesions like actinic keratosis, Bowen's disease, xeroderma pigmentosa and radiation dermatitis [7].

Eyelid malignancies are completely treatable if detected early. Early diagnosis of eyelid growth is thus of extreme importance to avoid high morbidity and mortality.

Although, eyelid lesions are common in clinical practice, no systematic study has yet been performed in Bangladesh. Therefore, the present study was conducted to determine the histological types of eyelid lesions among the patients attending teaching hospitals of Dhaka city.

\section{Materials and Methods}

This was a cross sectional study conducted at the Department of Pathology of Sir Salimullah Medical College, Dhaka, Bangladesh. Samples were collected form hospitals of SSMC and NIO. Study period was from January 2012 to December 2013. The study protocol was approved by the ethical committee of Sir Salimullah Medical College, Dhaka. Ref: Memo. No / SSMC /294. Date: 06/09/ 2012.

Collection and processing of samples: A total of 93 patients with clinically diagnosed eyelid growth of both sex were enrolled in the study. All the patients presented with eyelid growth were examined by an ophthalmologist and complaints were recorded. After obtaining informed written consent, tumors were excised by the ophthalmologist and the specimens were collected by researcher for histopathology examination. The surgically excised specimens were preserved in $10 \%$ formalin solution. Size, shape and consistency of each specimen were recorded. Large specimens were cut sagitally into pieces and the very small ones were embedded as such and wrapped in wrapping paper and kept in cassettes and then placed in $10 \%$ formalin for overnight fixation. Following over night fixation in $10 \%$ formalin the tissue blocks were gradually dehydrated in ascending concentration of ethyl alcohol. The blocks were then cleared in xylene, impregnated in paraffin and then embedded in proper orientation in malted paraffin. Tissue sections of 5-7 um thick were prepared and stained with haematoxylin and eosin (H\&E) stains as described elsewhere [8].

\section{Results}

A total of 93 cases with eyelid growths attending the outpatient department of $\mathrm{NIOH}$ and SSMC hospital were included in the present study. Out of total 93 cases, males and females were almost equally distributed $(51.6 \%$ vs. $48.4 \%)$. The mean age of the study population was $43.2 \pm 17.4$ years (range 19 - 90 years). There was no significant difference $(p>0.05)$ of mean age of male and female cases.

Out of total 93 eyelid growth, $55.9 \%$ were benign lesions while $35.5 \%$ and $7.5 \%$ were malignant and non-neoplastic lesions respectively (Table-1). Benign lesions of the eyelid was significantly higher $(p<0.05)$ than that of malignant lesions. There was only one case of premalignant lesion in a 65 years old male. The most common location of the eyelid lesions was upper eyelid $(51.8 \%)$ while lower eyelids had $37.6 \%$ lesions.

Of the malignant lesions, basal cell carcinoma was $12(36.4 \%)$ followed by sebaceous gland carcinoma $9(27.27 \%)$ and squamous cell carcinoma 9 (27.27\%). Less common were nonHodgkin's lymphoma $2(6.06 \%)$ and small cell carcinoma $1(3.03 \%)$. Among 52 benign lesions, nevus was the most common $(14 / 26.9 \%)$, followed by sudoriferous cyst $(10 / 19.23 \%)$, haemangioma $(8 / 15.38 \%)$, squamous papilloma $(5 / 9.6 \%)$ and 
Paul R et al.

IMC J Med Sci 2017; 11(1): 5-10

Table-1: Gender and age distribution of the study population in relation to different eyelid lesions ( $n=93)$

\begin{tabular}{|c|c|c|c|c|c|c|c|c|c|}
\hline \multirow{2}{*}{$\begin{array}{l}\text { Eyelid } \\
\text { lesions }\end{array}$} & \multirow{2}{*}{$\begin{array}{l}\text { Total } \\
\text { No. }\end{array}$} & \multirow{2}{*}{$\begin{array}{c}\% \\
{[95 \% \mathrm{Cl}]}\end{array}$} & \multicolumn{2}{|c|}{ Male $(n=48)$} & \multicolumn{2}{|c|}{ Female $(n=45)$} & \multicolumn{3}{|c|}{$\begin{array}{c}\text { Age } \\
\text { Mean } \pm \text { SD in yrs }\end{array}$} \\
\hline & & & $\mathbf{N}$ & $\begin{array}{c}\% \\
{[95 \% \mathrm{Cl}]}\end{array}$ & $\mathrm{N}$ & $\begin{array}{c}\% \\
{[95 \% \mathrm{Cl}]}\end{array}$ & Male & Female & Total \\
\hline Benign & 52 & $\begin{array}{c}55.9 \\
{[45.8-65.9]}\end{array}$ & 29 & $\begin{array}{c}60.4 \\
{[46.6-74.2]}\end{array}$ & 23 & $\begin{array}{c}51.1 \\
{[36.5-65.7]}\end{array}$ & $33.6 \pm 12.3$ & $38.3 \pm 13.1$ & $35.9 \pm 12.6$ \\
\hline Malignant & 33 & $\begin{array}{c}35.5 \\
{[25.8-45.2]}\end{array}$ & 14 & $\begin{array}{c}29.2 \\
{[16.2-41.8]}\end{array}$ & 19 & $\begin{array}{c}42.2 \\
{[27.6-56.4]}\end{array}$ & $54.1 \pm 20.3$ & $58.5 \pm 17.8$ & $56.3 \pm 18.5$ \\
\hline $\begin{array}{l}\text { Non- } \\
\text { neoplastic }\end{array}$ & 7 & $\begin{array}{c}7.5 \\
{[\mathrm{NC}]}\end{array}$ & 4 & $\begin{array}{c}8.3 \\
{[\mathrm{NC}]}\end{array}$ & 3 & $\begin{array}{c}6.7 \\
{[\mathrm{NC}]}\end{array}$ & $26.3 \pm 5.2$ & $28.7 \pm 14.2$ & $27.3 \pm 9.0$ \\
\hline $\begin{array}{l}\text { Pre- } \\
\text { malignant }\end{array}$ & 1 & $\begin{array}{c}1.1 \\
{[\mathrm{NC}]}\end{array}$ & 1 & $\begin{array}{c}2.1 \\
{[\mathrm{NC}]}\end{array}$ & 0 & $\begin{array}{c}0 \\
{[\mathrm{NC}]}\end{array}$ & - & - & - \\
\hline
\end{tabular}

Note: $Z$ test was performed to compare the proportions. $p<0.05$, compared malignant and benign growth (55.9\% vs35.5\%) of study population; $p>0.05$, compared benign lesions of male and female cases (60.4\% vs 51.1\%); $p>0.05$, compared malignant lesions of male and female cases $(29.2 \%$ v $42.2 \%)$;

$C I=$ Confidence interval; $N C=$ Not calculated because of very low number of cases.

Table-2: Distribution of histologically diagnosed eyelid growths $(n=93)$

\begin{tabular}{lc}
\hline \multicolumn{1}{c}{ Eyelid Growth } & N (\%) \\
\hline A. Benign lesions (n=52) & \\
Nevus & $14(26.9)$ \\
Cyst of Moll/Hydrocystoma/ & $10(19.2)$ \\
Sudoriferous cyst & \\
Haemangioma & $8(15.4)$ \\
Squamous papilloma & $5(9.6)$ \\
Dermoid cyst & $5(9.6)$ \\
Epidermal inclusion cyst & $3(5.8)$ \\
Fibroepithelial polyp & $2(3.9)$ \\
Sebaceous cyst & $2(3.9)$ \\
Adenoma & $1(1.9)$ \\
Lipoma & $1(1.9)$ \\
Neurofibroma & $1(1.9)$ \\
A. Malignant lesions (n=33) & \\
Basal cell carcinoma & $12(36.4)$ \\
Sebaceous gland carcinoma & $9(27.3)$ \\
Squamous cell carcinoma & $9(27.3)$ \\
Non-Hodgkin's lymphoma & $2(6.0)$ \\
Small cell carcinoma & $1(3.0)$ \\
C. Non-Neoplastic lesions (n=7) & \\
Molluscum Contagiosum & $2(28.6)$ \\
Rhinosporodiosis & $2(28.6)$ \\
Chalazion/Lipogranuloma & $2(28.6)$ \\
Abscess & $1(4.3)$ \\
D. Premalignant lesion $(\mathbf{n}=\mathbf{1})$ & \\
Actinic keratosis & $1(100)$ \\
\hline &
\end{tabular}

dermoid cyst $(5 / 9.6 \%)$. Other less common lesions were epidermal inclusion cysts in 3 cases $(5.77 \%)$, and sebaceous cysts in 2 cases $(3.85 \%)$, fibroepithelial polyp 2 (3.85\%). adenoma $1(1.92 \%)$, lipoma $1(1.92 \%)$, neurofibroma $1(1.92 \%)$. There were 2 cases of rhinosporodiosis among non-neoplastic lesions. Detail distribution of histopthologically diagnosed eyelid growths is shown in Table-2.

\section{Discussion}

The present study was conducted with an aim to assess the histopathological types of eyelid growths. It was a hospital based cross sectional study which enrolled 93 clinically suspected eyelid growths. Out of them 86 were neoplastic and 7 were non- neoplastic growth. In our series we found $35.5 \%$ malignant and $55.9 \%$ benign growth. There was only one case of premalignant lesion. A study from Japan in 2012 has reported that out of 118 eyelid tumors that were removed and examined, $106(89.8 \%)$ were benign and 12 (10.2\%) were malignant [9]. Previous study in a tertiary care hospital in Thailand, has reported that out of 212 cases of eyelid tumor, $71.4 \%$ were benign and $10.8 \%$ were malignant [10]. We found a higher percentage of malignant growths. This might be due to the delay in seeking treatment because of lack of awareness, education and treatment facilities in rural areas, low socioeconomic status and less cosmetic concern.

In the present study, the majority of the patients (47 out of 93) were in the 26 to 50 years age group. Mean age of the study population in the 
present study was 43.2 years. Most of the malignant eyelid lesions were in patients above 51 years of age and benign growths were within the age group 26-50 years. Mean age of the patients with malignant lesions was 56.3 years and those with benign was 35.9 years. Both benign and malignant lesions of the eyelid were most commonly seen in patients in their forties and fifties [11]. Studies from Thailand, Taiwan and Japan have reported the mean age of diagnosis of eyelid cancers was between 52.4 to 72 years $[12,13,14]$. However, malignant tumors like squamous and basal cell carcinoma of the eyelid have been reported in patients below 25 years of age [15]. In the present study, we found squamous and basal cell carcinoma of eyelid in 21 and 22 years old patients.

Among the malignant tumors in the present study, most common was basal cell carcinoma (36.4\%) followed by sebaceous gland $(27.3 \%)$ and squamous cell carcinoma $(27.3 \%)$. In western countries, basal cell carcinoma is the most common among malignant eyelid tumors, whereas in Japan and other parts of Asia, the frequency of sebaceous gland carcinoma and squamous cell carcinoma are relatively high [14]. Sebaceous gland carcinoma tumor is more common in Asian countries, reportedly comprising $33 \%$ of eyelid tumors and second behind basal cell carcinoma [16]. The upper eyelid is involved 2 to 3 times more commonly than the lower eyelid. Women are affected more than men. The etiology of sebaceous carcinoma is not entirely known. Human papilloma virus and increased expression of TP53 gene has been implicated as genetic factor in invasive sebaceous gland carcinoma $[17,18]$. In the present study, sebaceous gland carcinoma was found in $27.3 \%$ cases with malignant tumors. Females (6 out of 9) were affected more than male. In the present study, squamous cell carcinoma was found in $27.3 \%$ malignant cases. Eyelid squamous cell carcinoma is an invasive tumor arising from the squamous cell layer of the skin epithelium and affects mainly elderly fair-skinned individuals. The most common risk factor is exposure to ultraviolet light. Most commonly, it involves the lower lid margin and inner canthus. It may arise de novo but often it may arise from preexisting lesions such as actinic keratosis, xeroderma pigmentosum, carcinoma in situ (Bowen's disease), or following radiotherapy [19].

In the present study, other less common malignant tumors were non-Hodgkin's lymphoma (2 cases) and small cell carcinoma (1 case). One case was histolologically diagnosed as actinic keratosis in the present study. Actinic keratosis (solar keratosis) is the most common precancerous cutaneous condition. It usually occurs in sun-exposed areas of the skin, including eyelids, and is a result of damage of the epidermal cells by near ultraviolet radiation. Actinic keratosis may transform to squamous cell carcinoma [20].

Among the benign lesions of eyelid, nevi were the most common in the present study. Out of 52 benign lesions, nevus was the most common (26.9\%), followed by sudoriferous cyst (19.2\%), haemangioma $(15.4 \%)$, squamous papilloma $(9.6 \%)$ and dermoid cyst $(9.62 \%)$. Other less common lesions were epidermal inclusion cysts, sebaceous cysts, fibro epithelial polyp, adenoma, lipoma and neurofibroma. Similar pattern of benign growth of eyelids were reported by others [21,22].

Non-neoplastic lesions namely, molluscum contagiosum, rhinosporodiosis, chalazion/and lipogranuloma were found in the present study. Chalazion is a very common localized lipogranulomatous inflammatory lesion of the sebaceous gland of the eyelid, most often of the meibomian gland. It usually occurs spontaneously due to noninfectious obstruction of sebaceous gland ducts [19]. Molluscum contagiosum are common skin lesions, seen more in children, caused by the pox virus that often affects the eyelid and the periocular skin [23]. Rhinosporidiosis caused by Rhinosporodium seberii presents as a polypoidal and vascular mass. Conjunctiva, lacrimal sac, sclera and eyelids are the most common ocular sites [24].

Eyelid is composed of heterogeneous tissue. Hence, we tend to see a variety of tumor types and subtypes, both benign and malignant. The early diagnosis of these tumors is essential for proper treatment and favorable prognosis. The present study has showed the pattern of eyelid tumors in our population. The information is important to ophthalmologists for accurate diagnosis of eyelid growths and its proper management. 


\section{References}

1. Abdi U, Tyagi N, Maheshwari V, Gogi R, and Tyagi SP. Tumors of eyelid: a clinicopathologic study. J Indian Med Assoc. 1996; 94(11): 405-409.

2. Myers M, Gurwood AS. Periocular malignancies and primary eye care. Optometry. 2001; 72(11): 705-712.

3. Pe'er J . Pathology of eyelid tumors. Indian J Ophthalmol. 2016; 64(3): 177-190.

4. Klintworth GK, Cummings TJ. The eye and ocular adnexia. In: Mills SE, Carter D, Greenson JK, Reuter VE, Stoler MH, editors. Sternberg's diagnostic surgical pathology, Vol. I. 5th ed. Philadelphia: Lippincott Williams \& Wilkins; 2009, p965.

5. Kersten RC, Ewing-Chow D, Kulwin DR, Gallon M. Accuracy of clinical diagnosis of cutaneous eyelid lesions. Ophthalmology. 1997; 104: 479-484.

6. Baron $\mathrm{K}$, Curling OM, Paridaens $\mathrm{AD}$ and Hungerford JL. The role of cytology in the diagnosis of peri-ocular basal cell carcinomas. Ophthal Plast Reconstr Surg. 1996; 12: 190-194.

7. Vemuganti GK and Rai NN. Neoplastic lesions of eyelids, eyeball and orbit. J Cytol. 2007; 24: 30-36

8. Gamble M, Wilson I. The hematoxylins and eosin. In: Bancroft JD, Gamble M, editors. Theory and practice of histological techniques. $5^{\text {th }}$ ed. Edinburgh: Churchill Livingstone; 2002; p130.

9. Toshida H, Mamada N, Fujimaki T, Funaki T, Ebihara N, Murakami A and Okisaka S, et al. Incidence of benign and malignant eyelid tumors in Japan. Int $J$ Ophthalmic Pathol. 2012; 1(2): 112-114.

10. Pornpanich K, Chindasub P. Eyelid tumors in Siriraj Hospital from 2000-2004. J Med Assoc Thai. 2005; 88 Suppl 9: S11-14.

11. Mondal SK and Dutta TK. Cytohistological study of eyelid lesions and pitfalls in fine needle aspiration cytology. J Cytol. 2008; 25(4): 133-137.
12. Lin HY, Cheng CY, Hsu WM, Kao WH and Chou P. Incidence of eyelid cancers in Taiwan: a 21-year review. Ophthalmology. 2006; 113(11): 2101-2107.

13. Pombejara FN, Tulvatana $\mathrm{W}$ and Pungpapong K. Malignant tumors of the eye and ocular adnexa in Thailand: a six-year review at King Chulalongkorn Memorial Hospital. Asian Biomed. 2009; 3: 551-555.

14. Takamura H, Yamashita H. Clinicopathological analysis of malignant eyelid tumor cases at Yamagata University hospital: statistical comparison of tumor incidence in Japan and in other countries. Jpn J Ophthalmol. 2005; 49: 349-354.

15. Nerad JA and Whitaker DC. Periocular basal cell carcinoma in adults 35 years of age and younger. Ophthalmology. 1988; 106: 723-729.

16. Kanski JJ. Clinical ophthalmology: a systematic approach. $5^{\text {th }}$ ed. Philadelphia PA: Butterworth Heinmann; 2003.

17. Hayashi N, Furihata M, Ohtsuki Y, Ueno H. Search for accumulation of p53 protein and detection of human papillomavirus genomes in sebaceous gland carcinoma of the eyelid. Virchows Arch. 1994; 424(5): 503-509.

18. Cottle DL, Kretzschmar K, Schweiger PJ, Quist SR, Gollnick HP, Natsuga K, et al. cMYC-induced sebaceous gland differentiation is controlled by an androgen receptor/p53 axis. Cell Rep. 2013; 3(2):427-441.

19. Font RL. Eyelids and lacrimal drainage system. In: Spencer WH, editor. Ophthalmic pathologyan atlas and textbook, vol. 4. 4th ed. Philadelphia: WB Saunders; 1996; p2229-2232.

20. Person JR. An actinic keratosis is neither malignant nor premalignant: it is an initiated tumor. J Am Acad Dermatol. 2003; 48: 637638.

21. Coroi MC, Rosca E, Mutiu G, Coroi T, Bonta M. Eyelid tumors: histopathological and clinical study performed in County Hospital of Oradea between 2000-2007. Rom J Morphol Embryo. 2010; 51(1):111-115.

22. Farhat F, Jamal Q, Saeed M, Ghaffar Z. Evaluation of eyelid lesions at a tertiary care 
10 IMC J Med Sci 2017; 11(1): 5-10

Paul R et al.

hospital, Jinnah Postgraduate Medical Centre (JPMC), Karachi. Pak J Ophthalmol. 2010; 26(2): 83-86.

23. Averbuch D, Jaouni T, Pe'er J, Engelhard D. Confluent molluscum contagiosum covering the eyelids of an HIV-positive child. Clin
Experiment Ophthalmol. 2009; 37: 525-527.

24. Pathak D, Neelaiah S. Disseminated cutaneous rhinosporidiosis: diagnosis by fine needle aspiration cytology. Acta Cytol. 2006; 50: 111-112. 